\section{Urologia \\ Internationalis}

\section{F.S. Van Rey \\ J.P.F.A. Heesakkers}

Department of Urology, The Radboud University Nijmegen Medical Centre, Nijmegen, The Netherlands
Urol Int 2008;81:373-378

DOI: $10.1159 / 000167831$

\title{
Applications of Neurostimulation for Urinary Storage and Voiding Dysfunction in Neurological Patients
}

Key Words

Neurogenic overactive bladder • Nerve stimulation • Neuromodulation

\begin{abstract}
The application of various forms of electrical stimulation is considered a therapeutic option to manage different types of lower urinary tract dysfunction. However, even though lower urinary tract dysfunction is common in patients with neurological disease, apart from patients with spinal cord injury, electrostimulation is still not widely applied in a neurological patient population. Urologists frequently encounter patients with neurogenic lower urinary tract dysfunction in their daily practice. Often, the conservative treatment modalities do not offer adequate relief of symptoms in these patients. In most cases, surgical options including transurethral stents, augmentation cystoplasty stoma or derivation surgery are considered a last resort. With this in mind, it is essential that healthcare professionals are informed about the possibilities of nerve stimulation in neurogenic patients. We review the utilization and the results of electrical stimulation by means of pudendal nerve stimulation, stimulation of the sacral nerve roots and lower limb stimulation in patients with neurogenic detrusor overactivity.
\end{abstract}

Copyright $\odot 2008$ S. Karger AG, Basel
(C) 2008 S. Karger AG, Basel 0042-1138/08/0814-0373\$24.50/0

Fax +41613061234 E-Mail karger@karger.ch www.karger.com

\section{Neuroanatomy and Pathophysiology}

Normal bladder function consists of storage and expulsion of urine. In order to do so, the lower urinary tract requires extensive input and control from the peripheral autonomic, somatic and central nervous systems. Abnormalities of any component of these control pathways may result in voiding dysfunction. The pontine micturition centres are connected to the sacral cord through transspinal pathways. Intact afferent and efferent pathways are necessary to initialize the reciprocal activity of the detrusor and sphincter needed to switch between storage and voiding (fig. 1).

During storage of urine, the goal is to achieve continence and maintain low intravesical pressure. This is for the better part regulated by the sympathetic nervous system. Originating from Th10-L2, the sympathetic efferent motor neurons travel to the pelvis, the hypogastric plexus. Here, they will synapse in the ganglia of the pelvic plexus. The sympathetic neuron will then innervate the dome of the bladder, the bladder neck and urethra through adrenergic transmission. The dome of the bladder contains mostly $\beta$-adrenergic receptors (providing relaxation of the muscle), whereas the bladder neck and urethra predominantly have $\alpha$-adrenergic receptors (providing contraction).

Afferent information about the degree of bladder filling originates from $A \delta$ fibres in the bladder wall and travels through the lumbosacral spinal cord via the pelvic and hypogastric nerves to local interneurons and higher levels of the central nervous system. If storage is to be main-

John Heesakkers

Department of Urology, The Radboud University Nijmegen Medical Centre Geert Grooteplein 10

NL-6500 GA Nijmegen (The Netherlands)

Tel. +31 24361 3735, Fax +31 24354 1031, E-Mail J.Heesakkers@uro.umcn.nl 


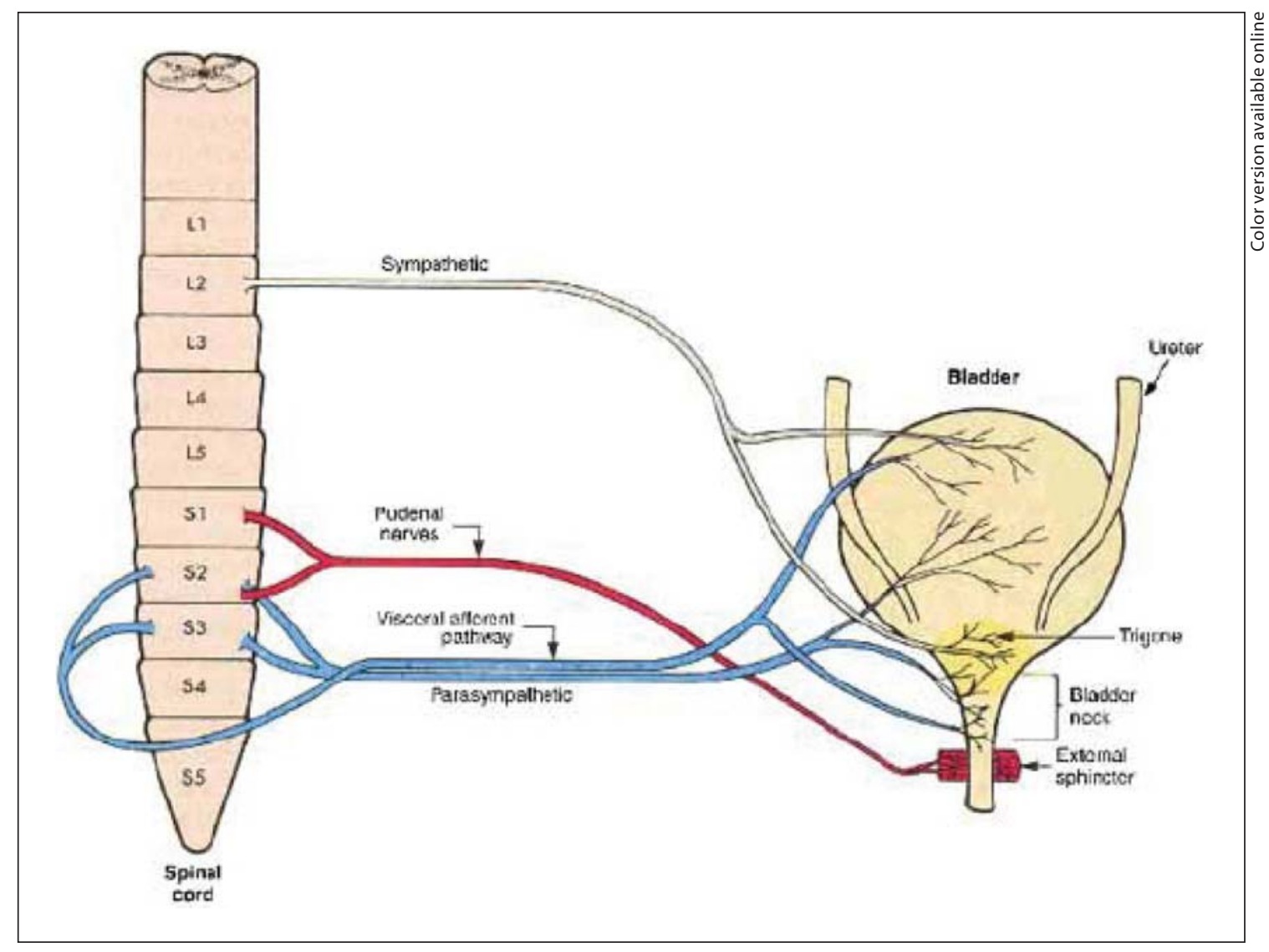

Fig. 1. Neuroanatomy and pathophysiology. With permission from Michael Craggs.

tained, the above-mentioned pathways will provide detrusor relaxation. Apart from relaxation of the bladder dome and contraction of the bladder neck initiated by the sympathetic nervous system, the so-called 'guarding reflex' provides a progressive, involuntary increase in the activity of the external urethral sphincter during bladder filling. With guarding reflex activation, it is believed that the afferent signals travel from the contracting external urethral sphincter via pudendal branches to the sacral cord and inhibit parasympathetic bladder motor neurons directly through spinal interneurons. Animal studies have shown that stimulation of the external urethral sphincter, through peripheral nerves (i.e. pudendal nerve and tibial nerve), results in inhibition of detrusor activity [1].

In case of bladder fullness and appropriate timing, the brain cortex will signal the pontine micturition centre. The pontine micturition centre will then stimulate parasympathetic preganglionic motor neurons in the sacral cord (originating from S2-S4), which in turn will activate postganglionic neurons in the pelvic ganglia. The muscarinic receptors located in the bladder are innervated by this parasympathetic input. Bladder contraction and the initiation of micturition is the result.

The somatic innervation of the rhabdosphincter is through the pudendal nerve. From S2-S4, where it originates, it travels trough the motor horn of the spinal cord directly to the muscle fibres of the external urinary sphincter. In this process, the muscarinic receptor is the receptor of use. The control of the external urinary sphincter is voluntary. Voiding is initiated with relaxation of the rhabdosphincter and ends with its contraction.

Neurological disorders will often cause various types of disturbances of lower urinary tract functioning. Damage to the central inhibitory pathways that inhibit the primitive voiding reflexes or sensitization of the peripheral afferent nerves to the bladder can trigger detrusor overactivity [2]. Spinal lesions above the sacral micturition centre may cause hyperreflexia and dyssynergia of 
the lower urinary tract [3]. Sequentially, bladder storage function may be compromised by elevated intravesical pressure and reduced functional capacity. This may result in urinary incontinence and chronic renal failure $[4$, 5]. In neurogenic diseases like spinal cord injury (SCI) patients, the pathways that connect the pontine micturition centre to the sacral cord are interrupted. Immediately after the SCI, the detrusor is usually acontractile for a period of several weeks. We refer to this period as 'the spinal shock phase'. After this period, 2 'detrusor external sphincter dyssynergia' (the sphincter contracts when the bladder is contracting) occur as a result of the lost reciprocal coordination between bladder and sphincter as well as reflex detrusor contractions. This is a result of the normally 'silent' C-fibres taking over afferent control, forming a spinal segmental reflex.

\section{Sacral Nerve Stimulation and Modulation}

\section{Sacral Nerve Stimulation}

Stimulation at the level of the sacral nerve roots is the most widely applied neurostimulation in neurogenic voiding dysfunction.

Stimulation of the anterior (efferent) axons of the sacral nerves (SARS - sacral anterior root stimulation), located intradurally in the cauda equina, has first been reported by Brindley [6]. Combining the stimulation of SARS with sacral deafferentation, in order to abolish hyper-reflexia and gain bladder capacity and compliance, was shortly thereafter described by Sauerwein [7] (fig. 2). After identifying and transecting the posterior sacral roots, the anterior roots of S2-S4 are placed in so-called electrode books. The connected leads are tunnelled subcutaneously to the anterior abdominal wall. There they are connected to a receiver block. An external stimulator operated by the patient transmits radiofrequency signals to the receiver block. These signals excite the sacral ventral roots. Stimulation is delivered to the sacral anterior roots to induce bladder contraction for bladder emptying. The electrical stimulation causes activation of small nonmyelinated efferent parasympathetic nerve fibres, directly inducing contraction of detrusor smooth muscles and external sphincter striated muscle. Bladder emptying is achieved by post-stimulus voiding: stimulation of the anterior roots results in both a contraction of the detrusor and the external urethral sphincter, but as the 'fast twitch' striated muscle fibres of the external sphincter contract and relax more quickly than the 'slow twitch' smooth muscle of the detrusor, intermittent stimulation will lead

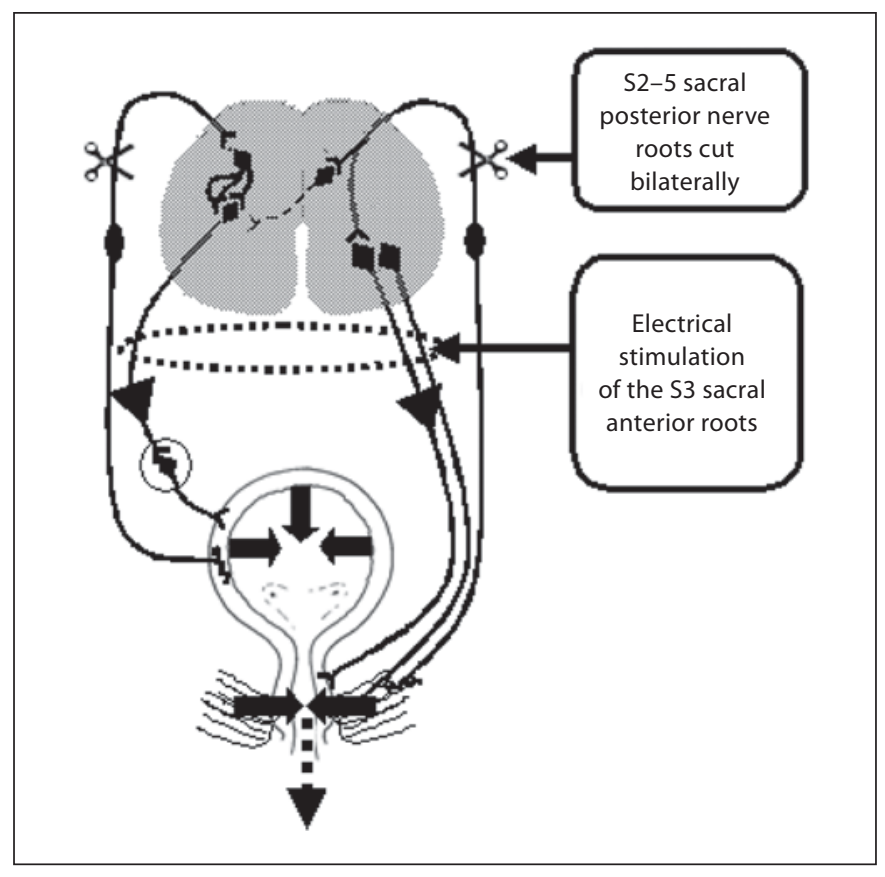

Fig. 2. Stimulation of the anterior (efferent) axons combined with deafferentation (posteriorly), as first reported by Brindley [6]. With permission from Michael Craggs.

to effective bladder emptying between the 2 stimulation pulses. Other substantial advantages are an increased bladder capacity and bladder compliance, as well as protection of the upper urinary tract due to the abolition of detrusor hyper-reflexia, which also improves the continence status. A disadvantage is weakness of the pelvic floor muscles. The technique is only applied to paraplegic patients, mostly SCI patients with a complete suprasacral lesion. Follow-up results of this technique show a great efficacy and safety and increase in quality of life in SCI patients $[8,9]$. Complete continence was achieved in 73$83 \%$ of the patients, and complications of urinary tract infections and deterioration of kidney function are only sporadically seen in patients with the implant. As a result of the complete dorsal rhizotomy, not only detrusor hyperreflexia is eliminated, but also a loss of reflex defecation and reflex erection/reflex lubrication will occur. In the majority of patients, efficient bowel emptying and/or erection/lubrication can also be achieved by stimulation.

The loss of reflex defecation and reflex erection/reflex lubrication as well as new developments in stimulation patterns have provoked a debate about the necessity of a complete dorsal rhizotomy. This led to the development of a sacral root stimulator technique using the established 


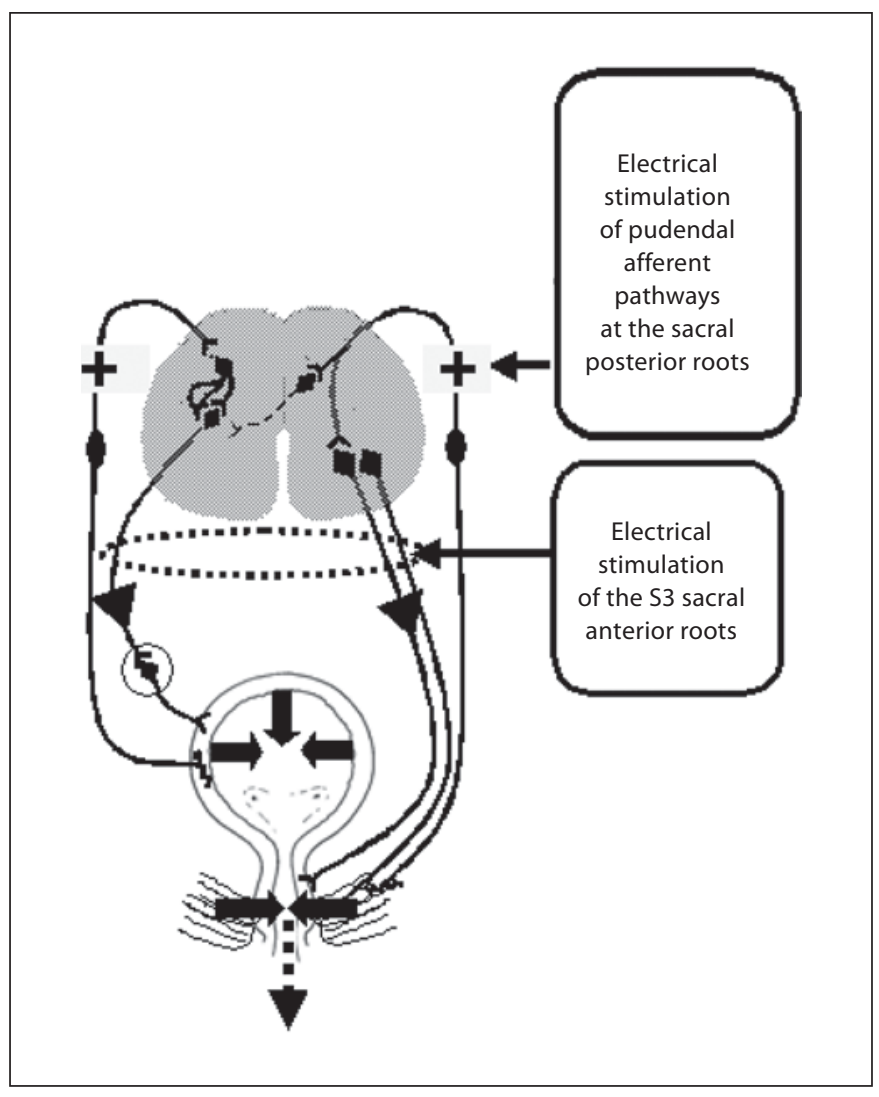

Fig. 3. Stimulation of the anterior and the posterior roots (SPARSI). With permission from Michael Craggs.

Finetech-Brindley stimulator combined with neuromodulation of the posterior sacral roots. Instead of the deafferentation, neuromodulation is used to suppress detrusor hyper-reflexia. This concept is called SPARSI (sacral posterior and anterior root stimulator implant) [10] (fig. 3). Both continued as well as conditional neuromodulation via a SPARSI was effective in 5 patients and may replace the need for rhizotomy. They do warrant caution in case of patients with persisting detrusor external sphincter dyssynergia, as it may prevent complete bladder emptying [10].

\section{Sacral Nerve Modulation}

In 1980, Illis et al. [11] reported the beneficial effects of spinal cord stimulation in multiple sclerosis (MS) patients. By introducing electrodes into the epidural space, percutaneous test stimulation could be carried out. In case of success, permanent stimulation was offered. They state that the bladder dysfunction is the manifestation of MS, which responds best to spinal cord stimulation. Spi- nal cord stimulation was first carried out with Davis and Geck electrodes and later with Avery or Medtronic electrodes $[12,13]$. This way of neuromodulation is the predecessor of neuromodulation through sacral afferent pathways.

Electrical stimulation of the sacral afferent (sensory) roots (through which pudendal afferents pass) has been shown to inhibit bladder contractions in animals as well as in humans [14]. Tanagho and Schmidt [15] observed that electrostimulation of the sacral root could inhibit inappropriate neural reflex behaviour. Stimulation of sacral roots can be achieved by implanting an electrode in the sacral foramina (preferably S3), which is connected to a pulse generator placed subcutaneously. It is believed that the principles underlying the possible mechanisms for sacral neuromodulation can be summarized as somatic afferent inhibition of sensory processing in the spinal cord [16]. In the earlier studies for sacral neuromodulation, no report is made on whether patients with neurological conditions were eligible for inclusion [17, 18]. The first results of chronic stimulation of the sacral S3 nerve by using an implantable device in $4 \mathrm{MS}$ patients were published by Bosch and Groen [19]. They stated that sacral nerve stimulation (SNS) therapy is feasible and that it is a promising treatment option for selected MS patients. Chartier-Kastler et al. [20] reported on long-term results of SNS in the treatment of 9 patients with neurogenic refractory urge incontinence. In this study, which comprised 5 MS patients, $75 \%$ subjective improvement after a mean follow-up of 46 months was observed. Recently, Minardi et al. [21] published their preliminary report on 5 patients treated with sacral neuromodulation and they again state that SNS can be a valuable treatment for neurogenic bladder disorders associated with MS. Although several publications show that SNS can be of value in neurological patients, Scheepens et al. [22] found a 4 times higher chance of a negative test stimulation for SNS in neurological patients.

\section{Stimulation of the Peripheral Nerves}

\section{Dorsile Penile/Clitoral Nerve Stimulation}

The pudendal nerve originates in the nerve roots of S2-S4; it innervates the pelvic floor and external sphincter. The dorsal penile and clitoral nerves are the most superficial and exclusively afferent branches of the pudendal nerve. These branches have frequently been used for electrical stimulation, as they are inhibitory to the micturition reflex. In cat studies, spontaneous bladder con- 
tractions could be inhibited with stimulation of pudendal nerves [23]. The application of pudendal nerve stimulation in SCI patients showed a significant increase in cystometric bladder capacity, due to the inhibitory actions on the micturition reflex, with continuous electrical stimulation of the dorsal penile/clitoral nerve. Dalmose et al. [24] showed that also conditional electrical stimulation of the dorsal penile/clitoral nerve results in an inhibition of detrusor contractions in SCI patients with neurogenic detrusor overactivity (NDO), and therefore, an increase in bladder capacity. Even though the application of dorsal penile/clitoral nerve stimulation has been shown to be effective in inhibiting NDO and increasing bladder capacity in patients with SCI, the therapy is not widely applied, because a prerequisite for the clinical application of this treatment modality is a reliable stimulation technique. With the development of the implantable ministimulator for the pudendal nerve - the Bion device (Advanced Bionics, Sylmar, Calif., USA) [25] - and a minimally invasive procedure by Spinelli et al. [26] in which a tined lead is guided into the Alcock's canal next to the pudendal nerve, a beginning can be made in investigating the applicability of pudendal nerve stimulation.

Preliminary data of pudendal nerve stimulation with the tined lead in neurogenic patients with NDO show encouraging results [26]. Preliminary data on the acute effects of conditional stimulation of the dorsal penile/clitoral nerve with surface electrode in MS patients are consistent with the results in SCI patients [27].

\section{Tibial Nerve Stimulation}

Stimulation of the tibial nerve has first been described as a neuromodulatory treatment option by McGuire et al. [28] in 1983. By stimulating the tibial nerve at the site of the medial malleolus of the ankle, detrusor activity could be suppressed in normal and spinal injured non-human primates. The tibial nerve contains fibres originating from the spinal roots L4-S3. From this site, also the somatic and autonomic nervous supply to the pelvic floor originate. It is believed that through this crossover tibial nerve stimulation works. Transcutaneous stimulation progressed to percutaneous stimulation and was initially known as Stoller afferent nerve stimulation. Currently, it is known as posterior tibial nerve stimulation (PTNS) [29].

PTNS has a subjective efficacy of $63-64 \%$ and an objective efficacy of $46-54 \%$ in a non-neurogenic patient population with complaints of overactive bladder [30,31]. Little is known about its efficacy in patients with neurogenic lower urinary tract dysfunction. Petta et al. [32] state that PTNS is an effective option to treat detrusor hyperreflexia. Clinical improvement was seen in $64 \%$ in a patient population comprising MS, myelitis, incomplete SCI, stroke and Parkinson's disease. Finazzi et al. [33] report that PTNS is an interesting treatment option in patients with MS. Subjective improvement was observed in $8 / 11(73 \%)$ of MS patients.

\section{Considerations}

For many years now, electrical nerve stimulation and neuromodulation have been investigated and applied in the treatment of lower urinary tract dysfunction. Further optimizations of stimulation parameters and lead placement have made nerve stimulation/modulation a well-accepted treatment option in patients in whom conservative treatment has failed.

Although lower urinary tract dysfunction is very common in patients with a neurological condition, little clinical research is done in the field of nerve stimulation and neuromodulation apart from neurostimulation in SCI. This is remarkable since these therapies are intended to correct nerve misbehaviour, and neurogenic patients are therefore the most logic group of patients to benefit from these treatments.

The concepts of nerve regenerative treatments have induced renewed caution for the utilization of the FinetechBrindley technique, as described by Sauerwein [7]. It has led to new developments and modification of the technique (SPARSI). Further research in that field is being conducted to establish whether SPARSI can be as effective as SARS with posterior rhizotomy, especially with respect to the upper urinary tract. Implantation of a SPARSI device (without posterior rhizotomy) is so far not advised for patients with severe detrusor-external sphincter dyssynergia. Other developments are still in a preclinical phase.

Preliminary results of pudendal nerve stimulation in patients with a neurological condition show optimistic prospects. The long-term effects of pudendal nerve stimulation with implanted devices have to be awaited.

Even though neurogenic disease is considered a negative predictive factor for success, in MS patients, the available data show positive short- and long-term results. Further research in SNS is needed in order to learn more about predictive factors for success and optimal stimulation parameters in neurogenic patients, but it could be an acceptable treatment option. 
Lower urinary tract dysfunction is a symptom in many neurological conditions (i.e. Parkinson's disease, bifid spine, cerebrovascular disease, diabetes); unfortunately, conservative treatment often fails in these patients. Nerve stimulation and neuromodulation in these patients should also be considered before engaging in non-reversible surgical options.

\section{Conclusions}

Electrical nerve stimulation and neuromodulation has been widely and successfully applied in patients with SCI. In other neurological conditions leading to bladder misbehaviour, little research is done and extensive clinical evidence is lacking.

\section{References}

1 McGuire E, Morrissey S, Zhang S, Horwinski E: Control of reflex detrusor activity in normal and spinal injured non-human primates. J Urol 1983;129:197-199.

2 de Groat WC: A neurologic basis for the overactive bladder. Urology 1997;50(suppl $6 \mathrm{~A}): 36-52$

-3 Kaplan SA, Chancellor MB, Blaivas JG: Bladder and sphincter behavior in patients with spinal cord lesions. J Urol 1991;146:113-117.

4 Abrams P, Kelleher CJ, Kerr LA, Rogers RG: Overactive bladder significantly affects quality of life. Am J Manag Care 2000;6 (suppl 11):S580-S590.

5 Lawrenson R, Wyndaele JJ, Vlachonikolis I, Farmer C, Glickman S: Renal failure in patients with neurogenic lower urinary tract dysfunction. Neuroepidemiology 2001;20: 138-143.

6 Brindley GS: Emptying the bladder by stimulating sacral ventral roots. J Physiol 1974; 237:15P-16P.

7 Sauerwein D: Surgical treatment of spastic bladder paralysis in paraplegic patients. Sacral deafferentation with implantation of a sacral anterior root stimulator. Urologe A 1990;29:196-203.

8 Kutzenberger J, Domurath B, Sauerwein D: Spastic bladder and spinal cord injury: seventeen years of experience with sacral deafferentation and implantation of an anterior root stimulator. Artif Organs 2005;29:239241.

-9 van Kerrebroeck PE, Koldewijn EL, Rosier PF, Wijkstra H, Debruyne FM: Results of the treatment of neurogenic bladder dysfunction in spinal cord injury by sacral posterior root rhizotomy and anterior sacral root stimulation. J Urol 1996;155:1378-1381.

$\checkmark 10$ Kirkham AP, Knight SL, Craggs MD, Casey AT, Shah PJ: Neuromodulation through sacral nerve roots 2 to 4 with a FinetechBrindley sacral posterior and anterior root stimulator. Spinal Cord 2002;40:272-281.

11 Illis LS, Sedgwick EM, Tallis RC: Spinal cord stimulation in multiple sclerosis: clinical results. J Neurol Neurosurg Psychiatry 1980; 43:1-14

12 Breivik K, Engedal H, Segadal L, Ohm OJ: New temporary pacing lead for use after cardiac operations. J Thorac Cardiovasc Surg 1982;84:787-794.
13 Nashold BS Jr, Grimes J, Friedman H, Semans J, Avery R: Operative stimulation of the neurogenic bladder. Neurosurgery 1977; 1:218-220

14 Tai C, Booth AM, de Groat WC, Roppolo JR: Bladder and urethral sphincter responses evoked by microstimulation of S2 sacral spinal cord in spinal cord intact and chronic spinal cord injured cats. Exp Neurol 2004; 190:171-183

15 Tanagho EA, Schmidt RA: Electrical stimulation in the clinical management of the neurogenic bladder. J Urol 1988;140:1331-1339.

-16 Leng WW, Chancellor MB: How sacral nerve stimulation neuromodulation works. Urol Clin North Am 2005;32:11-18.

-17 Siegel SW, Catanzaro F, Dijkema HE, Elhilali MM, Fowler CJ, Gajewski JB, et al: Longterm results of a multicenter study on sacral nerve stimulation for treatment of urinary urge incontinence, urgency-frequency, and retention. Urology 2000;56(suppl 1):87-91.

18 Schmidt RA, Jonas U, Oleson KA, Janknegt RA, Hassouna MM, Siegel SW, et al: Sacral nerve stimulation for treatment of refractory urinary urge incontinence. Sacral Nerve Stimulation Study Group. J Urol 1999;162: 352-357.

19 Ruud Bosch JL, Groen J: Treatment of refractory urge urinary incontinence with sacral spinal nerve stimulation in multiple sclerosis patients. Lancet 1996;348:717-719.

20 Chartier-Kastler EJ, Ruud Bosch JL, Perrigot M, Chancellor MB, Richard F, Denys P: Long-term results of sacral nerve stimulation (S3) for the treatment of neurogenic refractory urge incontinence related to detrusor hyperreflexia. J Urol 2000;164: 1476-1480.

21 Minardi D, Muzzonigro G: Lower urinary tract and bowel disorders and multiple sclerosis: role of sacral neuromodulation. A preliminary report. Neuromodulation 2005;8: 176-181.

22 Scheepens WA, Jongen MM, Nieman FH, de Bie RA, Weil EH, van Kerrebroeck PE: Predictive factors for sacral neuromodulation in chronic lower urinary tract dysfunction. Urology 2002;60:598-602.

23 Jiang CH, Lindstrom S: Prolonged enhancement of the micturition reflex in the cat by repetitive stimulation of bladder afferents. J Physiol 1999;517:599-605.
24 Dalmose AL, Rijkhoff NJ, Kirkeby HJ, Nohr M, Sinkjaer T, Djurhuus JC: Conditional stimulation of the dorsal penile/clitoral nerve may increase cystometric capacity in patients with spinal cord injury. Neurourol Urodyn 2003;22:130-137.

25 Bosch JL: The bion device: a minimally invasive implantable ministimulator for pudendal nerve neuromodulation in patients with detrusor overactivity incontinence. Urol Clin North Am 2005;32:109-112.

-26 Spinelli M, Malaguti S, Giardiello G, Lazzeri M, Tarantola J, van den Hombergh U: A new minimally invasive procedure for pudendal nerve stimulation to treat neurogenic bladder: description of the method and preliminary data. Neurourol Urodyn 2005;24:305309.

27 Voss Fjorback M, Rijkhoff NJ, Petersen T, Nohr M, Sinkjaer T: Conditional electrical stimulation of the dorsal penile/clitoral nerve for management of neurogenic detrusor overactivity in multiple sclerosis. Paris, ICS, 2004.

28 McGuire E, Morrissey S, Zhang S, Horwinski E: Control of reflex detrusor activity in normal and spinal injured non-human primates. J Urol 1983;129:197-199.

29 van Balken MR, Vandoninck V, Gisolf KW, Vergunst H, Kiemeney LA, Debruyne FM, et al: Posterior tibial nerve stimulation as neuromodulative treatment of lower urinary tract dysfunction. J Urol 2001;166:914-918.

30 Vandoninck V, Van Balken MR, Finazzi AE, Petta F, Caltagirone C, Heesakkers JP, et al: Posterior tibial nerve stimulation in the treatment of urge incontinence. Neurourol Urodyn 2003;22:17-23.

-31 Vandoninck V, van Balken MR, Finazzi AE, Petta F, Micali F, Heesakkers JP, et al: Percutaneous tibial nerve stimulation in the treatment of overactive bladder: urodynamic data. Neurourol Urodyn 2003;22:227-232.

32 Petta F, Finazzi AE, Bemelmans BL, Vandoninck V, D’Amico A, Germani S, et al: Percutaneous stimulation of the posterior tibial nerve for the treatment of detrusor hyperreflexia. Seoul, ICS, 2001.

33 Finazzi AE, Parisi A, Petta F, Musco S, Virgili G, Caltagirone C: Percutaneous tibial nerve stimulation in the treatment of lower urinary tract dysfunction secondary to multiple sclerosis. Florence, ICS, 2003. 